\title{
Design and Analysis of 2-in-1 DC/DC Converter Trainer with Reduced Number of Components
}

\author{
A. A. Bakar", A. F. H. A. Gani, H. A. M. Ridzuan, A. Ponniran, M. U. Wahyu, M. A. N. Amran \\ Faculty of Electrical and Electronic Engineering, Universiti Tun Hussein Onn Malaysia, Malaysia
}

Received August 5, 2019; Revised October 12, 2019; Accepted December 12, 2019

Copyright $\odot 2019$ by authors, all rights reserved. Authors agree that this article remains permanently open access under the terms of the Creative Commons Attribution License 4.0 International License

\begin{abstract}
The field of power electronics around the world has shown a growth in its development, rising as a specialization in electrical engineering. Along these lines, for further comprehension of the field's theory, universities should take the lead in developing equipment for hands-on practical training. Several converter trainer kits exist in the market from many companies. A review of previous designs gives adequate ideas on the basics of the trainer and the components used in the trainer. The higher number of components used in the trainer significantly increases the cost, size and complexity of the system. Therefore, this paper outlines the design and development of a DC/DC converter trainer with buck and boost configurations. The proposed 2-in-1 DC/DC converter trainer can be configured as buck or boost at a time. The DC/DC converter comprises identical components but with different circuit configuration and operation. The circuit parameters are first calculated. To verify the effectiveness and functionality of the proposed trainer, a prototype is tested and compared with the simulation results from MATLAB/Simulink software. The proposed trainer uses Field-Programmable Gate Array (FPGA) to generate the Pulse-Width Modulation (PWM) signals. The findings obtained show that both theoretical simulation and experimental results align with each other. The results show that the proposed trainer can be designed with identical parameter components under certain constraints and conditions.
\end{abstract}

Keywords DC/DC Converter Trainer, Buck, Boost

\section{Introduction}

In recent years, the field of power electronics has witnessed an extraordinary growth in research and development around the world, rising as a specialisation in electrical engineering. The expansion of technology is the main trait foreseen to propel the industry's development interest in electrical engineering learning [1]-[4]. Moreover, electrical engineers are involved in depth in projects, from conceptualisation to maintenance. Along these lines, for further comprehension of the field's theory, universities should take a lead in developing equipment for hands-on practical training in order to upgrade useful aptitudes [5], [6]. Subsequently, training kits are essential learning material to enrich the hands-on skills on circuit connection and troubleshooting in certain engineering or technology courses. For example, in power electronics courses, a DC/DC converter training kit gives a platform as a learning device for the fundamentals of power conversion with different topologies [7]-[9].

A DC/DC converter is a device that changes direct current (DC) from one voltage level to another. There are different types of power converter being used, such as switched-mode DC/DC converters or switched-mode power supply (SMPS) [7], [10], [11].

Firstly, a buck converter, or otherwise called as a step-down converter, steps down voltage by increasing current at its input (supply) to the output (load). A buck converter is utilised in many popular applications for such as USBs, point-of-load (POL) converters for PCs and laptops, battery chargers, solar chargers, power audio amplifiers, pure sine wave power inverter to power household electronic devices from a large battery or a car, and brushless motor controllers [12].

Secondly, a boost converter, also known as a step-up converter, steps up input voltage to a greater level required by a load. There are quite a lot of applications of a boost converter, such as automotive applications (used in infotainment and cluster, gateway and body safety electronics applications), wearables (smartwatch, smart clothing, smart patch), adaptive control applications (low power orientation tracker, Bluetooth), TVs, set-top boxes and printers [13], [14].

In short, DC/DC converters are utilised as part of numerous applications for electronic circuits and DC 
electric engines, changing DC voltage to a higher or lower level. Nowadays, various controllers such as Digital Signal Controller (DSC) and Field-Programmable Gate Array (FPGA) are used in a closed-loop system and to generate Pulse-Width Modulation (PWM) signals.

In light of all the above, this research focuses on designing a DC/DC converter trainer for research laboratories. The trainer contains two circuits: buck and boost DC/DC converters which comprise identical components but with different circuit configuration and operation. It is an experimental training board, designed as a learning material for power electronics courses. Therefore, students will be able to comprehend the configuration and operation of buck and boost converters.

\section{Previous Designs}

This literature review involves a vast survey of trainers in the market from many manufacturers. The literature gives an adequate idea on the basics of the trainer and essential elements used in the trainer. Parts of various technical specification used for the trainer are discussed in detail in [12], [15]-[17]. Table 1 shows the gaps of study of a number of DC/DC trainer modules available in the market.

Table 1. The different designs of trainers

\begin{tabular}{|c|c|c|c|c|}
\hline Type of trainer & Buck & Boost & Buck-Boost & $\begin{array}{c}\text { Circuit } \\
\text { connected }\end{array}$ \\
\hline $\begin{array}{l}\text { Ni-Tech (National } \\
\text { Infotech), } \\
\text { "Switch Mode } \\
\text { DC/DC Converter } \\
\text { Trainer" [18] }\end{array}$ & $\sqrt{ }$ & $\sqrt{ }$ & $\sqrt{ }$ & $\sqrt{ }$ \\
\hline $\begin{array}{l}\text { Thepra, } \\
\text { "Automotive } \\
\text { DC/DC Converter } \\
\text { Trainer" [17] }\end{array}$ & $\sqrt{ }$ & $\sqrt{ }$ & & $\sqrt{ }$ \\
\hline $\begin{array}{l}\text { Vi Microsystem Pvt. } \\
\text { Ltd. } \\
\text { "MOSFET-based } \\
\text { Buck, Boost, } \\
\text { Buck-Boost } \\
\text { Converter Trainer" } \\
{[15]}\end{array}$ & $\sqrt{ }$ & $\sqrt{ }$ & $\sqrt{ }$ & $\sqrt{ }$ \\
\hline $\begin{array}{l}\text { Microtech Industry, } \\
\text { "Buck and Boost } \\
\text { Converter" }[16]\end{array}$ & $\sqrt{ }$ & $\sqrt{ }$ & & \\
\hline $\begin{array}{l}\text { Proposed trainer, } \\
\text { "2-in-1 DC/DC } \\
\text { converter trainer" }\end{array}$ & $\sqrt{ }$ & $\sqrt{ }$ & & \\
\hline
\end{tabular}

Recently, DC/DC converters are generally utilised in renewable energy application, for example, solar photovoltaic panels, wind turbines, fuel cells, batteries and hybrid systems. Over recent years, rapid advances in power electronics technology have been beneficial in the perspective of potentially better trainers in the market [2]. The power electronics course covers the fundamentals of converters such as DC/DC, DC/AC, AC/AC and AC/DC converters. Of a concern is the necessity for future engineers to be skilful in hands-on experiments in power electronics courses.

Nowadays, a few companies have manufactured power electronics training kits for power electronics application. The training or laboratory module gives specific explanation or instruction for users on specific topics concerning features for teaching material such as an educational experiment and integrates a training system with a complete curriculum of power electronics theory. The prices proportionally increase with the increasing complexity of the training kit.

National Infotech [12] has developed the "Non-Isolated Switch Mode DC/DC Converter" trainer kit, which includes buck, boost and buck-boost converter circuits. These circuits are able to operate in continuous current mode $(\mathrm{CCM})$ and discontinuous current mode (DCM) set-ups. Moreover, a microcontroller-based control circuit is used to produce a switching frequency of $40 \mathrm{kHz}$. In addition, the circuit can be operated in open-loop and closed-loop operations with provision for observing inductor voltage and current waveforms. Meanwhile, [19] in "MODEL VSMPS-064" has produced a "DC-DC Buck Converter Trainer", which consists of individual circuit trainer. Each circuit trainer includes a DC/DC converter module with buck, boost and buck-boost converters. The training kit consists of a voltage control circuit and a PWM generator with open-loop and closed-loop operations. However, these trainers are connected to each other according to their configuration. It also comes with individual circuit module. Therefore, the size and cost will significantly increase.

Despite these issues, the proposed 2-in-1 DC/DC converter trainer kit comes with a simpler, more compact and lighter design with the fewer number of of components. The buck and boost DC/DC converters have identical components; therefore, those components can be used to form two indistinguishable converters. Moreover, the fewer number of components can decrease the cost significantly as compared to the training kits in [19], [12]. In addition, Field-Programmable Gate Array (FPGA) is used as a controller to generate Pulse-Width Modulation (PWM) switching signals in order to regulate the output voltage as in [20], [21]. Meanwhile, the closed-loop system is realised as in [22]. 
Table 2. Gaps of study

\begin{tabular}{|c|c|c|c|c|c|c|c|}
\hline \multirow{2}{*}{ Type of trainers } & \multirow{2}{*}{ Specifications } & \multirow{2}{*}{$\begin{array}{l}\text { Switch } \\
\text { regulator }\end{array}$} & \multicolumn{5}{|c|}{ Components } \\
\hline & & & Inductor & Capacitor & Diode & Switch & Resistor \\
\hline $\begin{array}{l}\text { Ni-Tech (National Infotech), } \\
\text { "Switch Mode DC/DC } \\
\text { Converter Trainer" }\end{array}$ & $\begin{array}{l}\text { Input supply } 24 \mathrm{~V} \mathrm{DC} \text {, } \\
\text { Frequency } 40 \mathrm{kHz}\end{array}$ & MOSFET & 2 & 3 & 3 & 3 & 1 \\
\hline $\begin{array}{c}\text { Thepra, } \\
\text { "Automotive DC/DC } \\
\text { Converter Trainer" }\end{array}$ & $\begin{array}{l}\text { Input supply } 12 \mathrm{~V} \mathrm{DC} \text {, } \\
\text { Adjustable frequency }\end{array}$ & MOSFET & 2 & 2 & 2 & 2 & 2 \\
\hline \multirow{6}{*}{$\begin{array}{l}\text { Vi Microsystem Pvt. Ltd. } \\
\text { "MOSFET-based Buck, } \\
\text { Boost and Buck-Boost } \\
\text { Converter Trainer" }\end{array}$} & \multirow{6}{*}{$\begin{array}{l}\text { Input supply } 15 \mathrm{~V} \mathrm{DC} \text {, } \\
\text { Adjustable frequency }\end{array}$} & \multirow{6}{*}{ MOSFET } & \multicolumn{5}{|c|}{ Buck } \\
\hline & & & 1 & 1 & 1 & 1 & 1 \\
\hline & & & \multicolumn{5}{|c|}{ Boost } \\
\hline & & & 1 & 1 & 1 & 1 & 1 \\
\hline & & & \multicolumn{5}{|c|}{ Buck-Boost } \\
\hline & & & 1 & 1 & 1 & 1 & 1 \\
\hline $\begin{array}{c}\text { Microtech Industry, } \\
\text { "Buck and Boost Converter" }\end{array}$ & $\begin{array}{l}\text { Input supply } 5 / 10 \mathrm{~V} \text { DC, } \\
\text { Adjustable frequency }\end{array}$ & BJT & 1 & 1 & 1 & 1 & 1 \\
\hline \multirow{2}{*}{$\begin{array}{c}\text { Proposed trainer, } \\
\text { "2-in-1 DC/DC converter } \\
\text { trainer" }\end{array}$} & \multirow{2}{*}{$\begin{array}{l}\text { Input supply } 12 \mathrm{~V} \mathrm{DC} \text {, } \\
\text { Frequency } 40 \mathrm{kHz}\end{array}$} & & \multicolumn{5}{|c|}{ Buck or Boost } \\
\hline & & MOSFET & 1 & 1 & 1 & 1 & 1 \\
\hline
\end{tabular}

Table 2 shows the gaps of study of those trainers. The table shows the compilation of the proposed configuration, the switch regulator used and the quantity of components provided by each trainer. Most trainers use adjustable frequency and the range of input voltage is between 10-24 $\mathrm{V}$. The switch regulator used is MOSFET, which is the same as in the proposed trainer. Lastly, the quantity of components used depends on the circuit connection, as the trainer circuit is built-in with connections and with more than one component. If the built-in trainer does not have a connection, the quantity of component used is one each. This parameter may cause the difference in price, weight and size of the trainer. In short, in contrast to the trainers in the market, the idea of the proposed 2-in-1 DC/DC converter trainer is compacting two circuits into one trainer by compressing the elements necessary so as to minimise the size and weight. This will reduce the cost in order to compete with the trainers in the market nowadays.

\section{Proposed Design}

This project focuses on designing a DC/DC converter trainer with buck and boost configurations. A DC/DC converter trainer gives a platform for learning power conversion concepts and the differences in input and output circuits. It seems that numerous electronic trainers, especially DC/DC converter trainers, have not changed throughout the previous three decades. However, the converter's size and function may change due to the rapid advances in technology.

The objective of this 2-in-1 DC/DC converter trainer is to design an education kit for power electronics course. The main point for the trainer kit is to provide proficiency in hands-on experiment and a deep understanding of DC/DC converter's operation and principles. Figure 1 shows the general block diagram of the proposed system.

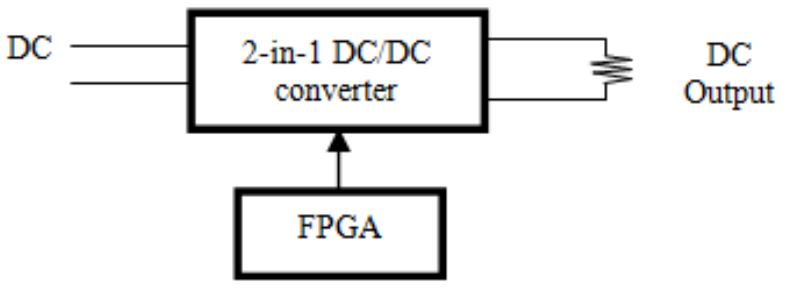

Figure 1. Block diagram of 2-in-1 DC/DC converter trainer

\subsection{Design Parameters}

This section briefly explains the selection of the component parameters, calculated using specific formulas. Firstly, there are certain critical parameters that need to be determined using mathematical calculations. To simplify the calculations, a few parameters are fixed as shown in Table 3.

Table 3. Fixed parameters

\begin{tabular}{|c|c|}
\hline Parameters & Value \\
\hline Voltage supply, $V_{s d}$ & $12 \mathrm{~V}$ \\
\hline Duty cycle, $D$ & 0.5 \\
\hline Frequency, $f$ & $40 \mathrm{kHz}$ \\
\hline Voltage ripple, $\Delta V_{o}$ & $0.1 \%$ \\
\hline Resistor, $\mathrm{R}$ & $50 \Omega / 100 \Omega$ \\
\hline
\end{tabular}

For a buck converter, the inductor's value needs to be determined. The value of inductor $L$ can be calculated using (1).

Minimum inductor, $L_{m i n}$ : 


$$
L \geq L_{\text {min }}=\frac{R(1-D)}{2 f}
$$

The value of inductor $L$ should be increased by $25 \%$ or greater $\left(L>>L_{\min }\right)$ than the minimum to ensure that the inductor current is continuous. Next, the value of the capacitor can be determined using (2).

$$
C_{L}=\frac{V_{o}(1-D)}{8 L \Delta V_{o} f^{2}}
$$

Meanwhile, for a boost configuration, the value of the inductor can be determined using (3).

Minimum inductor, $L_{\text {min }}$ :

$$
L_{\min }=\frac{D(1-D)^{2} R}{2 f}
$$

Afterwards, the capacitor's value can be calculated using (4).

$$
C=\frac{V_{o} D}{R \Delta V_{o} f}
$$

Let the inductor be $25 \%$ bigger than the minimum to ensure that the inductor current is continuous and the calculated value of the inductor for both buck and boost configurations in (1) and (3) can be determined using (5). In this condition, the buck converter is operated in continuous current mode if the value of the inductor is greater or equal to the calculated value. Therefore, in order to ensure that the system is operated in CCM mode for the all-inclusive duty cycle, the inductor's value is increased to $25 \%$.

$$
L=1.25 L_{\min }
$$

Table 4 shows the calculated and proposed value for the proposed 2-in-1 DC/DC trainer. The proposed inductor and capacitor is chosen to be $330 \mu \mathrm{H}$ and $470 \mu \mathrm{H}$, respectively. Those values have to be higher than the minimum values of the inductor and capacitor for current continuity purposes during the charging and discharging process of the inductor current. Besides, the maximum and minimum inductor currents also need to be emphasised as the permissible current passing through the inductor. Meanwhile, the chosen value of the capacitor as $470 \mu \mathrm{F}$ will ensure that the voltage output ripple is almost zero (less ripples).

Table 4. Calculated component parameter

\begin{tabular}{|c|c|c|}
\hline Converter & Inductor & Capacitor \\
\hline Buck $_{100 \Omega}$ & $625 \mu \mathrm{H}$ & $3.75 \mu \mathrm{F}$ \\
\hline Buck $_{50 \Omega}$ & $312.5 \mu \mathrm{H}$ & $7.5 \mu \mathrm{F}$ \\
\hline Boost $_{100 \Omega}$ & $156.25 \mu \mathrm{H}$ & $30 \mu \mathrm{F}$ \\
\hline Proposed & $330 \mu \mathrm{H}$ & $470 \mu \mathrm{F}$ \\
\hline
\end{tabular}

\subsection{Trainer Design}

Figure 2 shows the proposed layout of the 2 -in-1 DC/DC converter trainer kit's design. It consists of the arrangement of components and parts. The connection for each configuration (buck or boost) can be made with a single-wire banana connector. The detailed description of each part and component is depicted in Table 5.

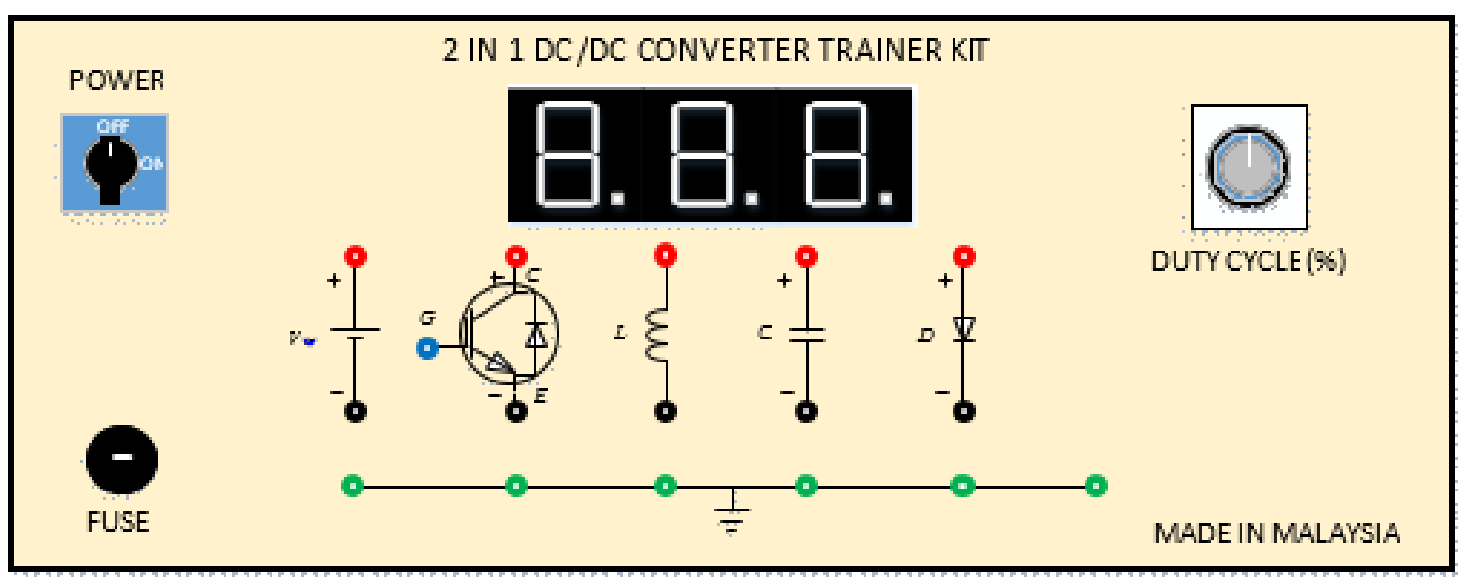

Figure 2. Proposed 2-in-1 DC/DC converter training kit 
Table 5. List of components and parts of trainer kits

\begin{tabular}{|l|l|l|}
\hline Name & Values & Description \\
\hline Seven-segment display & $5 \mathrm{~V}$ & To display the value of Pulse Width Modulation signal's duty cycle. \\
\hline Switch ON/OFF trainer & & To switch ON and OFF the trainer. \\
\hline DC Supply & $+12 \mathrm{~V}$ & Input supply from 3-pin 240 V/15 VDC. \\
\hline Fuse & $5 \mathrm{~A}$ & System protection. \\
\hline Adjustable Duty Cycle & $0 \%$ to $90 \%$ & Control the values of duty cycle by Altera DE Series board. \\
\hline Input PWM signal & $+15 \mathrm{~V}$ & PWM signal with 40 kHz switching frequency. \\
\hline Input voltage & $12 \sim 24 \mathrm{~V}$ & $\begin{array}{l}\text { Input voltage to supply ranges from } \\
5 \mathrm{~V} \text { to 20 V. }\end{array}$ \\
\hline MOSFET & $\mathrm{N}-\mathrm{Type}$ & Power switch for circuit triggering. \\
\hline Power inductor & $330 \mu \mathrm{H}$ & A two-terminal component which stores electrical energy in a magnetic field. \\
\hline Capacitor & $470 \mu \mathrm{F}$ & A passive two-terminal component that stores potential energy. \\
\hline Diode & Fast Switching Diode & $\begin{array}{l}\text { A two-terminal component that conducts current mainly in one direction with } \\
\text { low resistance. }\end{array}$ \\
\hline Variable resistor & 0 to $100 \Omega$ & A passive two-terminal component that functions as pure resistance load. \\
\hline
\end{tabular}

\section{Design Implementations}

This section offers insights on the methodology utilised to complete the project. The circuit design will be simulated with the end goal of comparing the result. The simulation for the circuit design utilises MATLAB/Simulink software.

\subsection{Simulation Using MATLAB/Simulink Software}

MATLAB/Simulink software is used to simulate the system before designing the hardware. It is used to confirm that the DC/DC converters work properly. Besides, it is also used to verify the calculations of the symmetrical component parameters used, before being applied in the hardware. The purpose of using this software is to analyze in detail the output voltage with respect to the changes of the duty cycle.

\subsection{PWM Switching Design}

The Quartus II software is used to design the switching scheme through the Field-Programmable Gate Array
(FPGA) board made by Intel Altera. The Quartus II structure programming gives a multiplatform design environment that readily adjusts to specific structure needs. The software is programmed using VHDL Hardware Description Language to describe the digital signal outputs. It is also capable of interfacing with analog signals by using an analog-to-digital converter.

Figure 3 shows the block diagram file (.bdf) for the PWM generator with $40 \mathrm{kHz}$ switching frequency. The block diagram consists of altpll, which is used to reduce the $50-\mathrm{MHz}$ internal clock of the Altera board to $40 \mathrm{MHz}$. The $40-\mathrm{MHz}$ output frequency is connected to the lpm_counter, which counts up from 0 to 999 for one complete cycle. This will represent $25 \mu$ s for one cycle of frequency. The output from the $1 \mathrm{pm}$-counter is then connected to the comparator block to generate the PWM switching signal. The comparator will compare the counter's output with the input signal as assigned in Table 6 to generate the PWM signals.

The bit setting for the counter is 11 bits; therefore, 11 toggle switches are assigned as the inputs. Table 6 shows the pin assignment's name list for each direction, location and description. These pins are used as references for the input and output connections. 


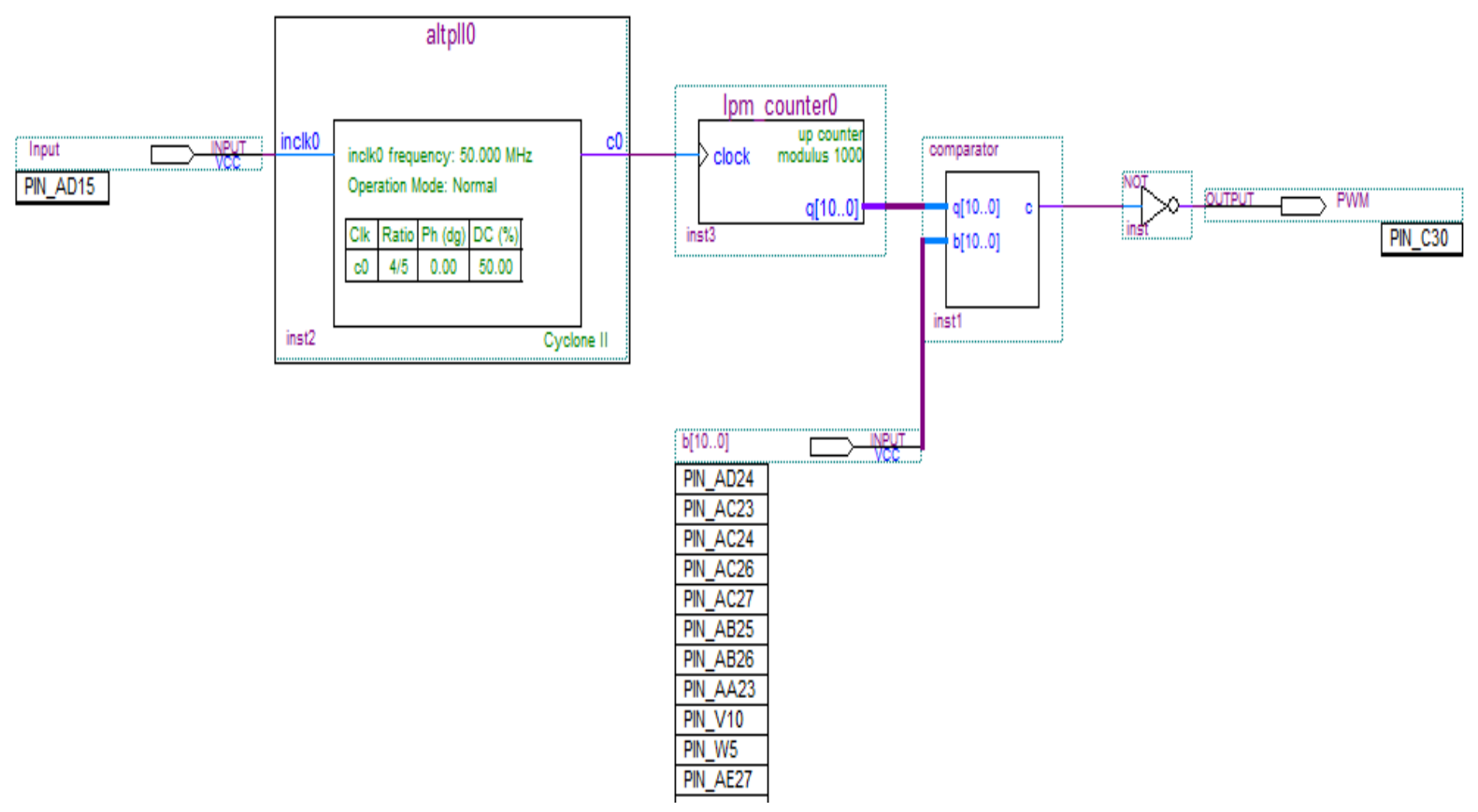

Figure 3. Block diagram for FPGA design for $40 \mathrm{kHz}$

Table 6. Pin assignments

\begin{tabular}{|c|c|c|c|c|}
\hline Name & $\mathrm{I} / \mathrm{O}$ & FPGA Pin & Signal Name & Description \\
\hline PWM & Output & PIN_C30 & IO_A [0] & GPIO Connection $0 \mathrm{IO}[0]$ \\
\hline $\mathrm{b}[0]$ & Input & PIN_AA23 & SW0 & Toggle Switch[0] \\
\hline $\mathrm{b}[1]$ & Input & PIN_AB26 & SW1 & Toggle Switch[1] \\
\hline $\mathrm{b}[2]$ & Input & PIN_AB25 & SW2 & Toggle Switch[2] \\
\hline $\mathrm{b}[3]$ & Input & PIN_AC27 & SW3 & Toggle Switch[3] \\
\hline $\mathrm{b}[4]$ & Input & PIN_AC26 & SW4 & Toggle Switch[4] \\
\hline $\mathrm{b}[5]$ & Input & PIN_AC24 & SW5 & Toggle Switch[5] \\
\hline $\mathrm{b}[6]$ & Input & PIN_AC23 & SW6 & Toggle Switch[6] \\
\hline $\mathrm{b}[7]$ & Input & PIN_AD24 & SW7 & Toggle Switch[8] \\
\hline $\mathrm{b}[8]$ & Input & PIN_AE27 & SW8 & Toggle Switch[9] \\
\hline $\mathrm{b}[9]$ & Input & PIN_W5 & SW9 & Toggle Switch[10] \\
\hline $\mathrm{b}[10]$ & Input & PIN_W10 & SW10 & Toggle Switch[11] \\
\hline
\end{tabular}

Table 7. The toggle switches for each duty cycle

\begin{tabular}{|c|c|c|c|c|c|c|c|c|c|c|c|c|}
\hline \multirow{2}{*}{$\begin{array}{c}\text { Duty Cycle } \\
(\%)\end{array}$} & $2^{10}$ & $2^{9}$ & $2^{8}$ & $2^{7}$ & $2^{6}$ & $2^{5}$ & $2^{4}$ & $2^{3}$ & $2^{2}$ & $2^{1}$ & $2^{0}$ & \multirow{2}{*}{ Decimal } \\
\hline & 1024 & 512 & 256 & 128 & 64 & 32 & 16 & 8 & 4 & 2 & 1 & \\
\hline 10 & 0 & 0 & 0 & 0 & 1 & 1 & 0 & 0 & 1 & 0 & 0 & 100 \\
\hline 20 & 0 & 0 & 0 & 1 & 1 & 0 & 0 & 1 & 0 & 0 & 0 & 200 \\
\hline 30 & 0 & 0 & 1 & 0 & 0 & 1 & 0 & 1 & 1 & 0 & 0 & 300 \\
\hline 40 & 0 & 0 & 1 & 1 & 0 & 0 & 1 & 0 & 0 & 0 & 0 & 400 \\
\hline 50 & 0 & 0 & 1 & 1 & 1 & 1 & 1 & 0 & 1 & 0 & 0 & 500 \\
\hline 60 & 0 & 1 & 0 & 0 & 1 & 0 & 1 & 1 & 0 & 0 & 0 & 600 \\
\hline 70 & 0 & 1 & 0 & 1 & 0 & 1 & 1 & 1 & 1 & 0 & 0 & 700 \\
\hline 80 & 0 & 1 & 1 & 0 & 0 & 1 & 0 & 0 & 0 & 0 & 0 & 800 \\
\hline 90 & 0 & 1 & 1 & 1 & 0 & 0 & 0 & 0 & 1 & 0 & 0 & 900 \\
\hline
\end{tabular}


Table 7 represents the binary-to-decimal conversion, which represents the exact duty cycle as generated digitally. The duty cycle can be adjusted manually by turning on (' 1 ') or off (' 0 ') the toggle switches.

\section{Simulation and Experimental Results}

This section discusses the results obtained from the simulation and experimental works. A hardware prototype is built, tested and compared with the simulation results. The simulation and experiment results for the buck configuration's output voltage are tabulated in Table 8 and shown in Figure 4. In average, the percentage difference between the experimental results compared to the simulation is $4.51 \%$. Most of the readings from the experimental results are slightly higher compared to the simulation results. Observing the recorded data, the output voltage decreases proportionally with the decrease of the duty cycle.

Table 8. Output voltage at $40 \mathrm{kHz}$ for simulation and experiment of DC/DC buck converter

\begin{tabular}{|c|c|c|}
\hline \multirow{2}{*}{ Duty cycle (\%) } & \multicolumn{2}{|c|}{ Output voltage, $V_{o}(\mathrm{~V})$} \\
\cline { 2 - 3 } & Simulation & Hardware \\
\hline 10 & 1.26 & 1.66 \\
\hline 20 & 2.64 & 3.00 \\
\hline 30 & 3.83 & 3.88 \\
\hline 40 & 4.86 & 4.68 \\
\hline 50 & 5.77 & 5.76 \\
\hline 60 & 6.87 & 7.08 \\
\hline 70 & 8.15 & 8.32 \\
\hline 80 & 9.43 & 9.56 \\
\hline 90 & 10.70 & 10.79 \\
\hline
\end{tabular}

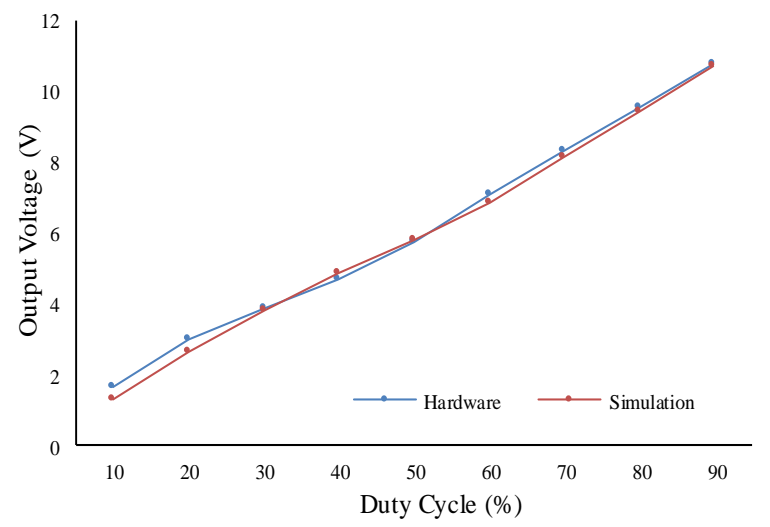

Figure 4. Graph of DC/DC buck converter output voltage from hardware and simulation

Meanwhile, the simulation and experimental results for the boost converter are shown in Table 9. Figure 5 represents the comparative analysis graph of the output voltage for the simulation and hardware of the boost converter with a variation of duty cycle. It can be observed that the average percentage difference in the output voltage between the simulation and hardware is approximately $1.42 \%$. The output voltage increases proportionally with the increase of the duty cycle.

Table 9. Output voltage at $40 \mathrm{kHz}$ for simulation and experiment of DC/DC boost converter

\begin{tabular}{|c|c|c|}
\hline \multirow{2}{*}{ Duty Cycle (\%) } & \multicolumn{2}{|c|}{ Output voltage, $V_{o}(\mathrm{~V})$} \\
\cline { 2 - 3 } & Simulation & Hardware \\
\hline 10 & 12.53 & 12.96 \\
\hline 20 & 14.20 & 14.64 \\
\hline 30 & 16.34 & 16.81 \\
\hline 40 & 19.19 & 19.70 \\
\hline 50 & 23.17 & 23.72 \\
\hline 60 & 29.11 & 29.67 \\
\hline 70 & 38.93 & 39.49 \\
\hline 80 & 58.09 & 55.19 \\
\hline
\end{tabular}

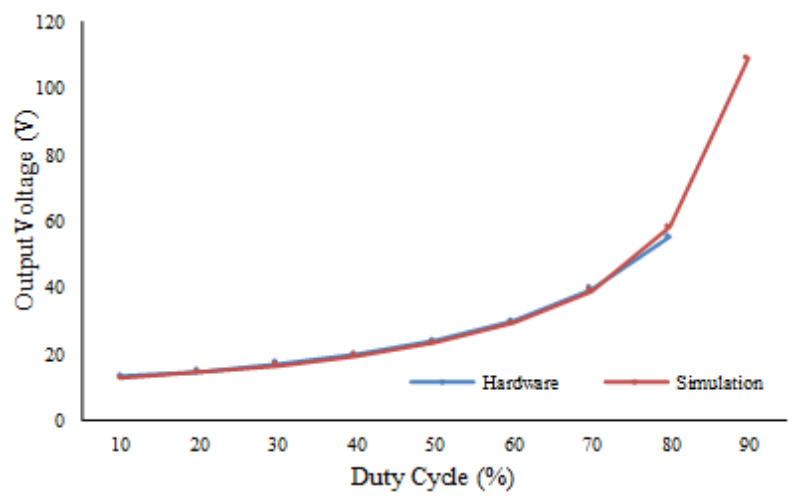

Figure 5. Graph of DC/DC boost converter output voltage from hardware and simulation

\section{Discussions}

Laboratory experiments are carried out using external variable DC input source and programmable electronic load as described as follows. The DC input source is adjustable so that the converter can operate with variable input voltage. Meanwhile, by using programmable electronic load, the load resistance can be controlled accurately. This is because, initially, the buck and boost nominal resistances are set to $50 \Omega$ and $100 \Omega$, respectively. Another reason is to ensure that the inductor current is in CCM condition for the preselected inductor. Besides, with the use of programmable electronics load, the capacitor will effectively discharge to the output load.

The trainer contains an FPGA board with power supply, adjustable PWM signal duty cycle with seven-segment indicator and associated components. Additional accessories or equipment are required, such as oscilloscope, DC power supply and programmable electronics load. At 
the beginning of the use of the design, the learning outcome from the trainer only covers enhancing the understanding of the fundamentals of circuit configuration, operation and connection and the characteristics or behaviour of the system. However, other learning outcomes have been identified and are possible to introduce, for example, the PWM switching signal design using Quartus II software. In addition, MATLAB/Simulink software can be used to verify the experimental results as a part of the trainer's learning outcome. For the next phase, proper documentation and supporting materials, including the laboratory and safety manuals and a set of laboratory exercises associated with the proposed converter will be prepared.

\section{Conclusions}

In this project, the simulation and hardware of the 2-in-1 DC/DC converter trainer kit are presented. By using FPGA, the output voltage can be varied by adjusting the duty cycle of the switching signals. In order to verify the functionality of the proposed converter, a prototype is tested and compared with the simulation. The 2-in-1 DC/DC trainer kit can be configured as a buck or boost converter and is tested and analysed with $12 \mathrm{~V}$ input source. Hardware data are recorded and compared with the simulation results to make sure that the switching signals and the components' values designed for this trainer are precise and in accordance with the theory. The findings show that the experiment and simulation results align with each other. In the 2-in-1 training module, the components used can be reduced by half compared to the conventional training modules.

\section{Acknowledgements}

The authors would like to express their deepest appreciation to Universiti Tun Hussein Onn Malaysia for supporting this research under TIER 1 Vot U195 research grant.

\section{REFERENCES}

[1] K. Store and P. Releases, "Power Electronics Market," 2018.

[2] Grand View Research, "Power Electronics Market Analysis By Material ( $\mathrm{Si}$, Sapphire, SiC, GaN, and Others), By Device (Discrete, Module, IC), By Application (ICT, Consumer Electronics, Power, Industrial, Automotive, Aerospace \& Defense), And Segment Forecasts, 20182025," 2017.

[3] P. Electronics, "Concept of Power Electronics," 2018.

[4] R. Mo, S. D. Sudhoff, W. Lafayette, S. F. Glover, and D. L.
Galloway, "Application of Power Electronics Today," 2000.

[5] B. Ozpineci, "Introduction to Power Electronics-A Tutorial," in Power Electronics and Electrical Power Systems Research Center.

[6] Indian Institute of Technology Kharagpur, "Power Semiconductor Devices," in Modul, Version 2, Indian Institutes of Technology, pp. 1-14.

[7] E. R. C. da Silva and M. E. Elbuluk, "Chapter 2Fundamentals of Power Electronics," in S. Chakraborty et al. (eds.), Power Electronics for Renewable and Distributed Energy Systems-A Sourcebook of Topologies, Control and Integration. Green Energy and Technology, 2013.

[8] A. P. Taylor and E. Astrium, "How to build a better DC/DC regulator using FPGAs,” pp. 1-8, 2018.

[9] H. L. Hess, B. Peterson, S. Elmore, and A. Mundy, "Hands-on Learning of Commercial Electrical Wiring Practices for Electrical Engineering Students Through Two-University Cooperative Effort," in 2013 ASEE Annual Conference \& Exposition, 2013.

[10] D. Knight, "Buck Converters and Their Cool Applications," All About Circuits, 2015.

[11] R. W. Erickson and D. Maksimović, Fundamentals of Power Electronics, Second ed. 2011.

[12] National Infotech, "Power Electronics Trainers," no. 202.

[13] P. Karthigeyan, M. S. Raja, T. S. Kumar, S. R. S. Ganesh, and J. Lavanya, "Simulation of Bi-directional DC-DC Converter Using FPGA," Procedia Comput. Sci., vol. 79, pp. 708-714, 2016.

[14] U. Sadek, A. Sarjaš, R. Svečko, and A. Chowdhury, "FPGA-based control of a DC-DC boost converter," IFAC-PapersOnLine, vol. 48, no. 10, pp. 22-27, 2015.

[15] Vi Microsystems, "Power Electronics Trainers."

[16] Microtech Industries, "Buck and Boost Converter Trainer," p., 2013.

[17] Thepra, “Automotive DC/DC,” vol. 49, no. 0, pp. 1-4, 2018.

[18] National Infotech, "National Infotech-power electronic training kits."

[19] Ali Shafique, Ijhar Khan, and S. A. R. Kashif, "Experiment-7-8-9 DC-DC converter," 2015.

[20] A. A. Bakar, W. M. Utomo, S. A. Zulkifli, E. Sulaiman, M. Z. Ahmad, and M. Jenal, "DC-DC Interleaved Boost Converter using FPGA," in IEEE Conference on Clean Energy and Technology, 2013, pp. 97-100.

[21] A. A. Bakar and H. Hashim, "Implementation of SCADA System for DC Motor Control," Int. Conf. Comput. Commun. Eng. (ICCCE 2010), no. May, pp. 11-13, 2010.

[22] A. B. Afarulrazi, M. U. Wahyu, T. Taufik, S. Aizam, and M. Yonis, "Design of Analog to Digital Converter for DC to DC Boost Converter with Constant Output Voltage," in The 3rd International Conference on Computer Engineering and Mathematical Sciences (ICCEMS 2014) Design, 2014, no. October 2015, pp. 800-804. 
[23] B. Ulrich, “A Modern, Versatile and Low Cost Educational System for Teaching DC/DC Converter Control with Analog, Digital and Mixed-Signal Methods," IEEE Baden-wuettemb. Coop. State Univ., pp. 5-12, 2017.

[24] I. Burhan, S. Talib, and A. A. Azman, "Design and fabrication of Programmable Logic Controller Kit with multiple output module for teaching and learning purposes," 2012 IEEE 8th Int. Colloq. Signal Process. Its Appl. CSPA 2012, pp. 14-18, 2012. 